\title{
Preliminary study of the production of metabolites from in vitro cultures of $C$. ensiformis
}

\author{
Juan F. Saldarriaga ${ }^{1 *}$, Yuby Cruz ${ }^{1}$ and Julián E. López ${ }^{2}$
}

\begin{abstract}
Background: Canavalia ensiformis is a legume native to Central and South America that has historically been a source of protein. Its main proteins, urease, and lectin have been extensively studied and are examples of bioactive compounds. In this work, the effect of $\mathrm{pH}$ and light effects on the growth of C. ensiformis were analyzed. Also, the bioactive compounds such as phenols, carotenoids, chlorophyll $\mathrm{a} / \mathrm{b}$, and the growth of callus biomass of $C$. ensiformis from the effect of different types of light treatments (red, blue and mixture) were evaluated. Likewise, the antioxidative activity of $C$. ensiformis extracts were studied and related to the production of bioactive compounds. For this, a culture of calluses obtained from seeds were carried out. For the light experiments, polypropylene boxes with red, blue, combination (1/3,3/1 and 1/1 R-B, respectively) lights and white LED were used as control. In each treatment, three glass containers with $25 \mathrm{ml}$ of MS salts containing $0.25 \mathrm{~g}$ of fresh callus were seeded.

Results: The results have shown that the $\mathrm{pH}$ of the culture medium notably affects the increase in callogenic biomass. It shows that the $\mathrm{pH}$ of 5.5 shows better results in the callogenic growth of $\mathrm{C}$. ensiformis with an average increase of $1.3051 \mathrm{~g}(198.04 \%)$, regarding the initial weight. It was found that the $\mathrm{pH} 5.5$ and the 1/3 R-B LED combination had higher production of bioactive compounds and better antioxidant activity. At the same time, the red-light treatment was least effective.

Conclusions: It was possible to find the ideal conditions of important growth under conditions of $\mathrm{pH}$ and light of C. ensiformis. Likewise, it is evaluated whether the production of compounds of interest, such as phenolic compounds and carotenoids, occurs under these conditions. The highest production of calluses occurs in the 1/3 RB LED combined light treatment, which showed a significant increase in biomass, followed by B. From this study, it could be demonstrated that $C$. ensiformis produces compounds such as phenols and carotenoids in vitro culture that are essential for the antioxidant activity of the plant.
\end{abstract}

Keywords: C. ensiformis, pH, LED blue, LED red, Bioactive compounds, In vitro culture

\footnotetext{
*Correspondence: jf.saldarriaga@uniandes.edu.co; juanfelorza@gmail.com ${ }^{1}$ Dept. of Civil and Environmental Engineering, Universidad de los Andes, Carrera 1Este \#19A-40, Bogotá, Colombia 111711

Full list of author information is available at the end of the article
}

(c) The Author(s). 2020 Open Access This article is licensed under a Creative Commons Attribution 4.0 International License, which permits use, sharing, adaptation, distribution and reproduction in any medium or format, as long as you give appropriate credit to the original author(s) and the source, provide a link to the Creative Commons licence, and indicate if changes were made. The images or other third party material in this article are included in the article's Creative Commons licence, unless indicated otherwise in a credit line to the material. If material is not included in the article's Creative Commons licence and your intended use is not permitted by statutory regulation or exceeds the permitted use, you will need to obtain permission directly from the copyright holder. To view a copy of this licence, visit http://creativecommons.org/licenses/by/4.0/ The Creative Commons Public Domain Dedication waiver (http://creativecommons.org/publicdomain/zero/1.0/) applies to the data made available in this article, unless otherwise stated in a credit line to the data. 


\section{Background}

In biochemical research, Canavalia ensiformis has been historically a promising source of protein [1]. Urease and lectin from $C$. ensiformis, are widely studied proteins and notable examples of the importance of bioactive compounds of this plant species [2-4]. In plants, the amount of these compounds depends mostly on the plants growing conditions (in vivo or in vitro), on the photoperiod to which it is exposed and on other important factors such as planting density, nutrient supply, temperature, etc. [5]. Therefore, the absorption of nutrients in plants grown in vitro are affected by several factors, such as gelling agents [6], the breakdown of carbohydrates and chelating agents [7]. Furthermore, it has been reported that light is a factor that can affect the production of these compounds [8-10], thereby inducing physiological changes in plants [11].

Extracellular $\mathrm{pH}$ can affect ion absorption and, at the same time, creates ionic competitions [12]. Studies have shown that low $\mathrm{pH}$ levels are associated with inhibition of cation absorption, while anion uptake may be slightly influenced or not influenced [12]. In particular, attention has focused on the effect of $\mathrm{pH}$ on nitrogen uptake by roots and on how the predominant form of nitrogen (i.e., $\mathrm{NH}_{4}{ }^{+}$or $\mathrm{NO}_{3}$ ) in the nutrient solution influences the absorption of the other ions [12-14].

Light is the origin of the direct source of energy for many plants as IT controls the growth rate in processes such as phototropism, photosynthesis, photomorphogenesis, among others that affect the metabolism related to pigments [15-17]. Four of the most important pigments are chlorophyll a (Chla), chlorophyll b (Chlb), phytochrome PR (red light) and PFR (far-red light), this according to Zhou et al. [16] and Wright [18]. These mainly absorb blue (400-500 nm), red (580-680), and far-red (690-800 nm) light. According to Carvalho et al. [19], the quality of these lights affects the accumulation of photosynthetic pigments in the leaves, which can increase absorption of light in low light conditions or act as screening pigments, and free radical scavengers in high light conditions. These effects have been extensively studied due these lengths are absorbed by photosynthetic pigments, and their important impact occurs in the development of plants [20,21]. Studies have found that the wavelengths of R and B always coexist in natural light environments and that the optimal mixture of these differs from the plant species. For example, for the strawberry, a $7 / 3$ ratio has been found [22]. In contrast, for rapeseed, a ratio $1 / 3$ [23] of the RB mix has been reported.

Chen et al. [24], argue that blue light is necessary during plant growth for normal photosynthesis and that the regulated responses of this plant quantitatively resemble those of irradiation intensity. Also, it was shown that plants cultivated in B have a higher proportion of Chl a/ $b$, more significant activity of Rubisco, and higher activity of transport of photosynthetic electrons than plants grown in R [25-28]. Also, B can trigger photomorphogenesis processes in plants and provides enough energy through photosynthesis to maintain normal growth and development [20]. Costa et al. [29] indicated that B is indispensable for photo-acclimatization and protection of diatoms at high light intensities.

On the other hand, plants that were grown with $\mathrm{R}$ exhibit a significantly lower $C h l a / b$ ratio, lower rates of photosynthetic $\mathrm{CO}_{2}$ fixation, and total plant biomass than plants grown with white light or a combination of $\mathrm{R}$ and $\mathrm{B}$ [28, 30, 31]. According to Wang et al. [28], plants are sensitive to their light environment not only because the light is the sole source of energy but also due to its effect on growth and development. An example of the above takes place in autumn, spring, and winter, where the shortening of the light time and the considerable fluctuation of irradiation are quite serious problems for the development of plants [28]. Plants that grow under low light intensity are more sensitive to photoinhibition caused by exposure to increase light irradiation [32].

In vitro tissue culture has been widely used for rapid plant propagation and obtaining bioactive compounds from cell culture [33]. There are previous studies of a successful induction and propagation of calluses of $C$. ensiformis under in vitro conditions [34]. However, the production of bioactive compounds such as photosynthetic pigments, phenols, and carotenoids from cell culture has not been evidenced for $C$. ensiformis. The main objective of this work was to evaluate different types of $\mathrm{pH}$ of the culture medium to determine the optimum in which the planting of $C$. ensiformis achieves adequate growth, and the production of metabolites of interest that can be used in its crops.

Furthermore, starting from the optimal $\mathrm{pH}$, the effect of different light treatments (red, blue, and combination), the production of chlorophyll, phenols, and carotenoids on the growth of callus biomass of $C$. ensiformis were evaluated. Also, the antioxidant activity of the extracts of C. ensiformis callus were analyzed, and these have related to the production of bioactive compounds. In this way, it was possible to determine under which light conditions, $\mathrm{R}, \mathrm{B}$, or combination present the best production of bioactive compounds and antioxidant activity.

\section{Results}

The results have shown that the $\mathrm{pH}$ of the culture medium notably affects the increase in callogenic biomass. Table 1 shows that the $\mathrm{pH}$ of 5.5 presents better results in the callogenic growth of $C$. ensiformis, with an 
Table 1 Callogenic biomass variation of C. ensiformis at different cultivation $\mathrm{pH}$

\begin{tabular}{llllll}
\hline Factor & $\mathrm{pH} 4.5$ & $\mathrm{pH} 5.0$ & $\mathrm{pH} 5.5$ & $\mathrm{pH} 5.7$ & $\mathrm{pH} 6.0$ \\
\hline Biomass initial weight (g) & 0.7321 & 0.6294 & 0.6590 & 0.6113 & 0.6519 \\
biomass final weight (g) & 1.3708 & 1.1858 & 1.9641 & 1.2449 & 1.2814 \\
average biomass increase (g) & 0.6387 & 0.6564 & 1.3051 & 0.6336 & 0.6295 \\
growth rate (\%) & 87.24 & 104.29 & 198.04 & 103.64 & 96.56 \\
\hline
\end{tabular}

average increase of $1.3051 \mathrm{~g}$ (198.04\%) after 30 days. While the $\mathrm{pH}$ of 6.0 evidences the least results of an increase in callogenic biomass. And finally, the $\mathrm{pH}$ of 5.0 and 5.7 show very similar results of biomass increase with approximately $104 \%$ on average for both treatments.

Table 2 shows the analysis of variance components for the effect of $\mathrm{pH}$ on callus growth, showing that $\mathrm{pH}$ is the most important factor in the effect of growth ( $p$ value 0.005$)$. It is observed as in the data in Table 1, that it is the $\mathrm{pH}$ of 5.5 that presents a positive effect on callus development. ANOVA shows that $\mathrm{pH}$ is the most significant factor and that it is important in callus growth. Of these, $\mathrm{pH} 5.5$ is the one with the highest percentage increase since planting after 30 days of planting. While the $\mathrm{pH}$ of 6.0 and 4.5 are the treatments that show lower results of biomass increase. With these results, it is shown that the optimal growth for a significant increase of biomass in vitro cultures of $C$. ensiformis, is with a $\mathrm{pH}$ of 5.5 .

\section{$D f:$ degrees of freedom.}

From these tests, the effect of the growth of calluses of C. ensiformis were evaluated in a medium with $\mathrm{pH} 5.5$ but with variation in the intensity of light.

\section{Effect of light on callus growth}

Figure 1 shows the effect of light on the growth of the C. ensiformis callus at 30 days, where it is observed that treatments with $B$ have a significant effect on the increase of weight of callus in this plant, having the highest production with the $1 / 3 \mathrm{R}-\mathrm{B}$ combination. While the treatments in which the $R$ is the main one, the increase in callus weight is smaller, being less than $0.35 \mathrm{~g}$ in all treatments.

Table 3 shows the statistical analysis regarding the increase of weight in calluses. According to the Tukey test, the combination of $1 / 3$ R-B LED represents an average increase of $1.08 \mathrm{~g}$. In contrast, white light and a combination of $3 / 1 \mathrm{R}$ and $\mathrm{B}$ LED with 0.28 , and $0.30 \mathrm{~g}$

Table 2 Analysis of variance for the effect of $\mathrm{pH}$ on growth

\begin{tabular}{lllll}
\hline Source & Sum of squares & $\boldsymbol{D} \boldsymbol{f}^{*}$ & Mean square & $\boldsymbol{p}$-value \\
\hline Total (corr.) & 256.6962 & 286 & & \\
pH & 16.6853 & 4 & 0.8177 & 0.0056 \\
Biomass initial weight & 240.0109 & 282 & 0.7123 & 0.0676 \\
\hline
\end{tabular}

respectively are below average. These results are engaging in the cultivation of $C$. ensiformis, because the rapid growth of calluses under these conditions helps to have enough biomass for the effects of a scaled process, or even on industrial levels.

\section{Total phenols content}

In Fig. 2, the effect of light on the production of phenolic/polyphenolic compounds is shown. It is observed that the production of phenolic compounds increased in all treatments with $\mathrm{B}$, compared to $\mathrm{W}$ (white light). In contrast, treatment with $\mathrm{R}$ resulted in a much lower mean than that of $\mathrm{W}$. These results may be related to the production of calluses, because the combination of 1/3 R-B LED produced more calluses, results in higher accumulation of total phenolics.

After applying statistical analysis and a Tukey test to the effect of light on the production of phenolic compounds, it was observed that there is a higher production of phenolic compounds when treatment $B$ is in equal or more significant proportion than $R$. The principal effect of the light occurs in the combined light treatments $1 / 3 \mathrm{R}-\mathrm{B}$ LED and 1/1 R-B LED with an average phenolic production of 11.52 and $10.75 \mathrm{mg} \mathrm{GAE} / \mathrm{g} \mathrm{FW}$, respectively.

\section{Chlorophyll $\mathrm{a}$ and $\mathrm{b}$ content}

The effect of light on the production of both Chla and Chlb is shown in Fig. 3. It is observed that in both treatments, the white light has a production above the average of all the Chlb treatments, while the Chla is given below the average of all the treatments. However, the highest production is of Chla, which reaches an average of $0.32 \mathrm{mg} \mathrm{g}^{-1}$ biomass while the Chlb is $0.24 \mathrm{mg} \mathrm{g}^{-1}$ biomass.

The combination of $1 / 3$ R-B LED and the treatment $B$ has higher concentrations of Chla and Chlb (Fig. 3a and b), this is because it has been widely proven that $B$ favors photosynthesis processes. An interesting effect is observed in the production of Chla compared to Chlb in the $1 / 3$ R-B and $B$ treatment in which the highest chlorophyll productions occur because Chla has a higher production with $0.5 \mathrm{mg} \mathrm{g}^{-1}$ biomass compared to Chlb of $0.3 \mathrm{mg} \mathrm{g}^{-1}$ biomass. In the case of Chlb, there is a higher standard deviation and a more extensive range. Figure 3 shows that the three best treatments to produce Chla and Chlb are the combination 1/3 R-B LED, B LED, and W LED. Of the above, the treatment of $1 / 3 \mathrm{R}-$ $B$ LED is the one with the highest concentration of both chlorophyll a and b with an average of 0.49 and $0.31 \mathrm{mg}$ $\mathrm{g}^{-1}$ biomass, respectively. Moreover, treatment with $\mathrm{R}$, has a lower concentration of chlorophyll both Chla and $C h l b$, demonstrating that exposing $C$. ensiformis only to $\mathrm{R}$ to produce Chla and Chlb is not adequate. 


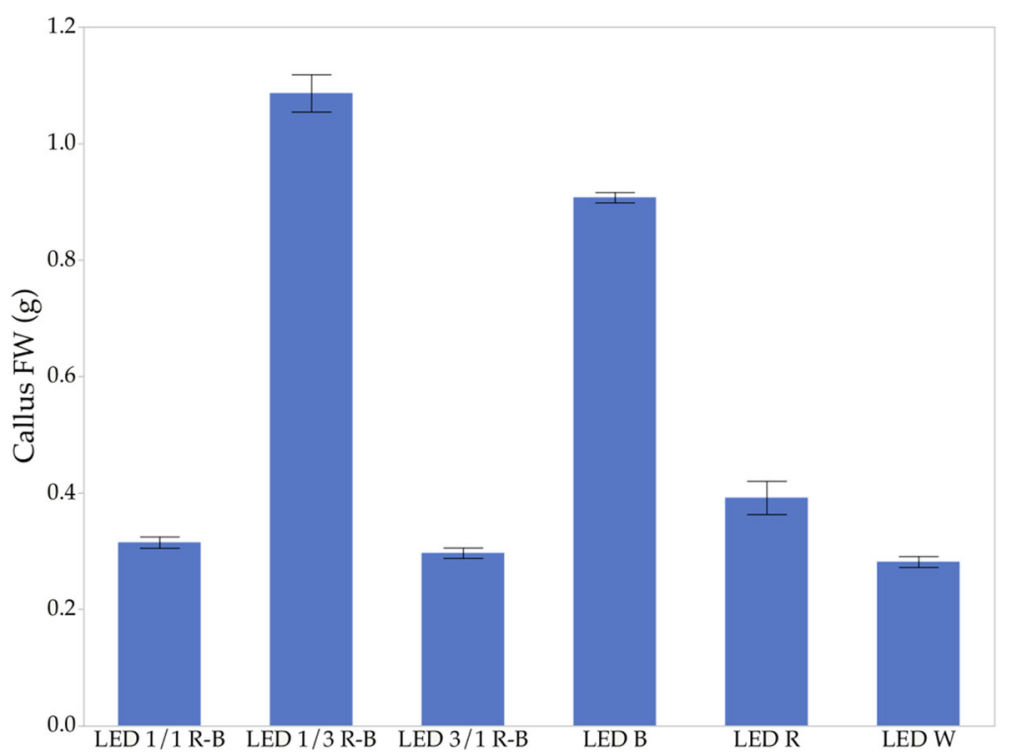

Fig. 1 Effect of lights on weight increase of callus

\section{Carotenoids content}

Regarding the production of carotenoids, observed in Fig. 4, the $\mathrm{R}$ is the one that presents the least number of carotenoids and, again, as in the previous results, it is the light with the lowest production response of bioactive compounds. In the case of the $1 / 3 \mathrm{R}-\mathrm{B}$ combination, it is the best response in the production of carotenoids with an average of $0.25 \mathrm{mg} \mathrm{g}^{-1}$ biomass. This combination is the one that had the best response to the production of compounds of interest and also in the callogenic production, even much greater than that of the control with W. Similarly, only B presented good results, all of them above average in each of the parameters evaluated.

\section{Antioxidant activity capacity}

According to the evaluation carried out on the antioxidant capacity of C. ensiformis callus extracts from different light treatments, it could be evidenced that B is the one that has the best effect on this parameter evaluated.

Table 3 Statistical analysis of the effect on increasing callus weight

\begin{tabular}{lllll}
\hline Level & Number & Mean & $\begin{array}{l}\text { Lower end } \\
\text { of 95\% Cl* }\end{array}$ & $\begin{array}{l}\text { Top end } \\
\text { of 95\% Cl* }\end{array}$ \\
\hline LED B & 3 & $0.910 \pm 0.021$ & 0.869 & 0.962 \\
LED R & 3 & $0.403 \pm 0.064$ & 0.243 & 0.563 \\
LED 1/3 R-B & 3 & $1.084 \pm 0.078$ & 0.889 & 1.279 \\
LED 1/1 R-B & 3 & $0.315 \pm 0.017$ & 0.273 & 0.357 \\
LED 3/1 R-B & 3 & $0.296 \pm 0.022$ & 0.242 & 0.351 \\
LED W & 3 & $0.282 \pm 0.023$ & 0.225 & 0.339 \\
\hline
\end{tabular}

${ }^{*} \mathrm{Cl}$ : Confidence interval
Conversely, the $\mathrm{R}$ is the one with the lowest activity, with an average of $30.67 \mu \mathrm{mol} \mathrm{TE} \mathrm{g}^{-1} \mathrm{FW}$. The same behavior is observed in the production of phenols and carotenoids concerning the higher antioxidant activity, in which the $B$ in equal or greater quantity than $R$ favors a better production of bioactive compounds (Table 4). Similarly, Table 4 shows that the standard deviation of all treatments is very low compared to the production of Chla and Chlb.

\section{Principal component analysis PCA}

The PCA analysis offers a graphical representation that simplifies the visualization and understanding of data and variables. The analysis shows a relationship between the factors and the different parameters measured. An interaction between Chla and Chlb is observed, in the same way, there is a correlation between the content of phenols and carotenoids (Fig. 5).

From the PCA analysis, it was found that the first two components explained $92.37 \%$ of the overall variation. A high positive correlation was observed between the antioxidant activity and the content of phenols and carotenoids. Callus weight had also shown a positive correlation with the chlorophyll content. The treatments mainly influence this with $B$ and the combination of $R$ and $B$. Likewise, Table 5 shows the analysis of six principal components showing the percentage of each one.

\section{Discussion}

It could be verified that the $\mathrm{pH}$ is an important factor in the increase of the biomass of $C$. ensiformis, this may be because it affects the intake of minerals, as well as the activity or metabolism of the phytohormones supplied in 


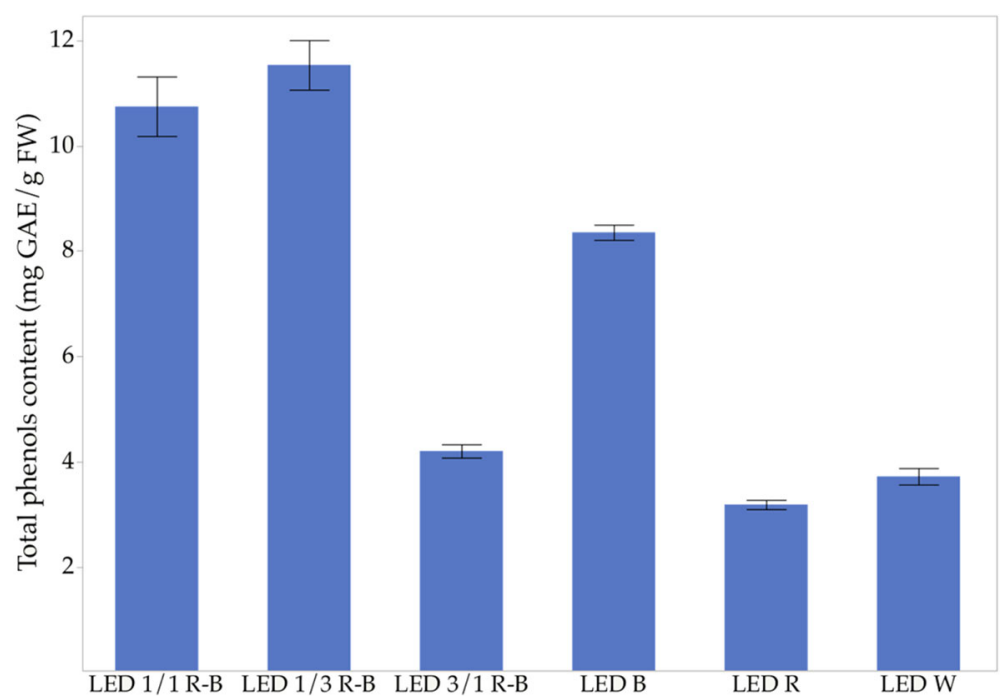

Fig. 2 Effect of light on the production of phenolic/polyphenolic compounds

the medium $[35,36]$. In the literature, there is little or no work on the effect of $\mathrm{pH}$ on in vitro cultures of C. ensiformis, considering that this parameter is essential and that depending on it, the plant will take nutrients better. Its development will also be optimum. Similarly, it has been proven that $\mathrm{pH}$ has a profound effect on crop productivity as primary metabolism and biosynthetic pathway enzymes are affected by culture media $\mathrm{pH}$ [37-40].

Studies have evaluated on other plants the $\mathrm{pH}$ effect on the growth of plants such as tomatoes, Catharanthus roseus, Withania somnifera, carrot, Bacopa monnieri, ectomycorrhizal fungi, among others [37, 41-47]. For this reason, the optimal $\mathrm{pH}$ for the in vitro culture of $C$. ensiformis is 5.5 . From this, the preliminary production of metabolites such as phenolic compounds and carotenoids were evaluated, as well as antioxidant activity.

In the case of $C$. ensiformis to date, there are few studies on the effect of light on callogenic growth, the production of phenols, chlorophyll $\mathrm{a} / \mathrm{b}$, carotenoids, and antioxidant activity. In this study, it was found that B positively affects callus weight, and these results again demonstrate that the light with this wavelength is necessary during plant growth for normal photosynthesis to occur. Similarly, the data accord with other authors who evaluated this light in other plant species [24]. The results of this study show that the considerable increase occurs in a combination of $1 / 3$ R-B LED, and this agrees with other authors who argue that these wavelengths are mostly absorbed by photosynthetic pigments giving an

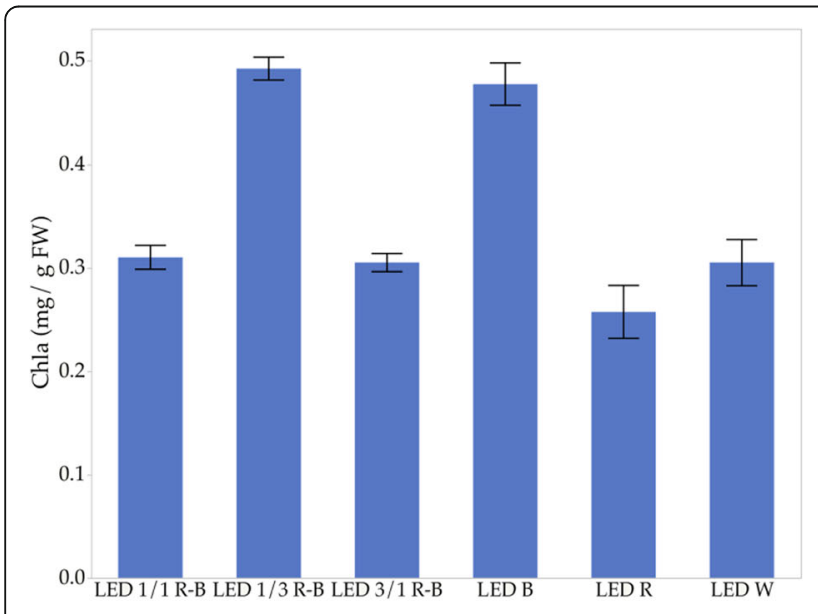

(a)

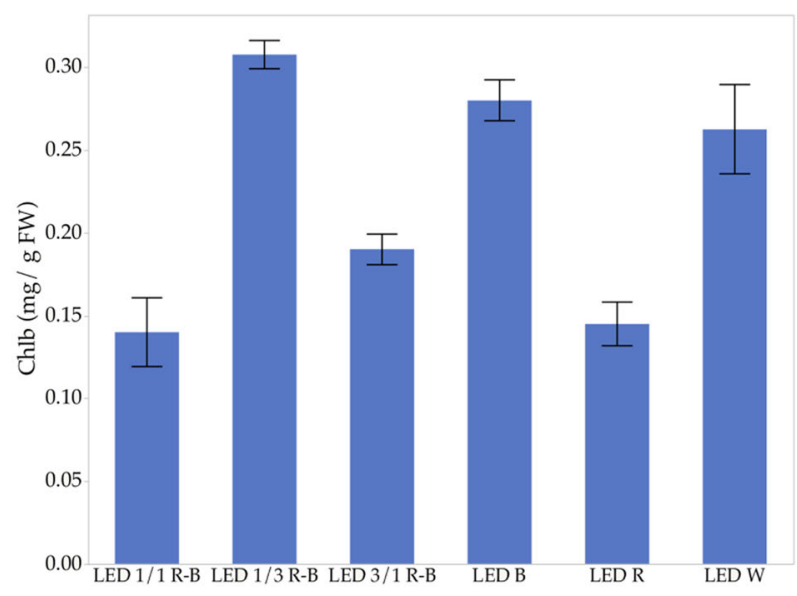

(b)

Fig. 3 Effect of light on chlorophyll production, (a) Chla and (b) Chlb 


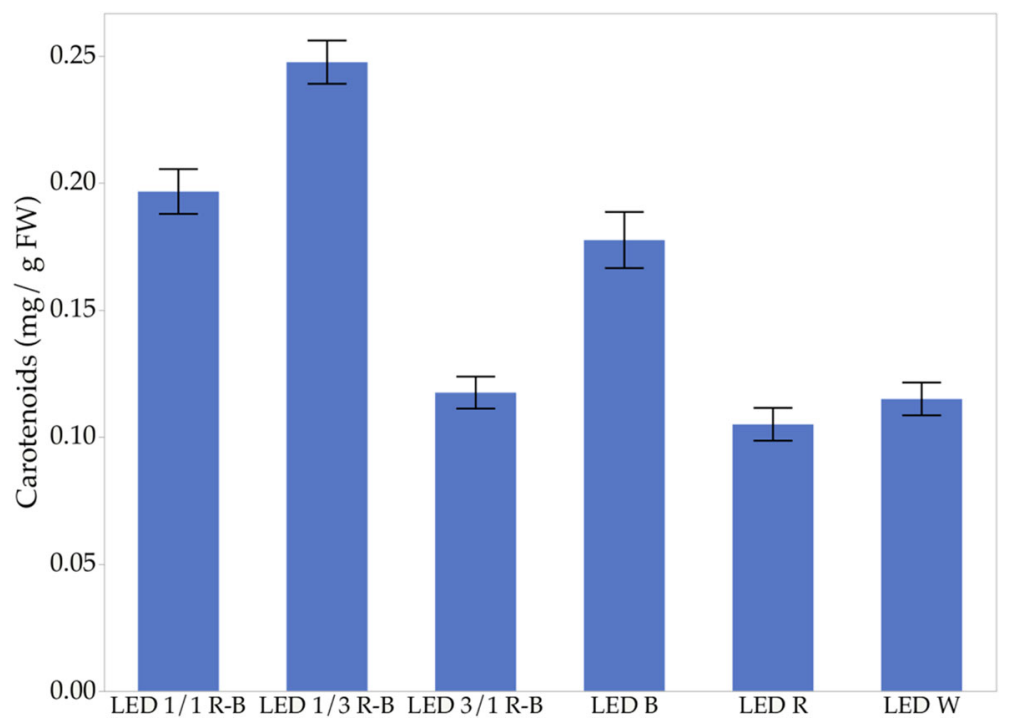

Fig. 4 Effect of lights on carotenoid production

important impact on development $[21,48]$. While other authors have found different R-B ratios, in the case of this study (the best $1 / 3 \mathrm{R}-\mathrm{B}$ ratio), which agrees with the results of Li et al. [23] for rapeseed, regarding the biomass increased. Likewise, this behavior is similar to what was argued by Ahmed et al. [49], which says that this type of spectra promotes plant growth, photosynthetic velocity, and biomass accumulation.

Concerning the production of chlorophyll, the same results were exposed as in other studies where it was found that with $\mathrm{R}$ the $\mathrm{Chl} a / b$ production is significantly low compared to $\mathrm{B}$ and $\mathrm{W}[28,31]$. In the case of $\mathrm{B}$, this work found that there is a production equal or higher than the $1 / 3$ R-B LED combination. These results coincide with other studies in which it was found that this favors the production of $C h l a / b$ [25-27]. With these results, those argued by other authors are proven that B is essential for the development of chloroplasts, stoma opening, and photomorphogenesis, as well as regulating the biosynthesis of chlorophyll and anthocyanin [50-53]. Also, it was proven with the results that a mixture of lights is necessary for the normal growth of the plant since it favors normal photosynthesis, and besides, the response of the plant can quantitatively resemble those found in the intensity of the radiation [24].

C. ensiformis shows a significant association between antioxidant capacity, phenols, and carotenoids. These results are similar to those found by Hoffmann et al. [54], which have shown that $B$ illumination favors the potential accumulation of carotenoids. Figure 6 is observed as the correlation between phenolic compounds and the antioxidant capacity, which is directly proportional and accords with other authors who report within the chemical compounds with antioxidant capacity, are the phenolic compounds [55]. Kapoor et al. [10] observed a higher production of phenolic compounds in in vitro cultured corns of the Rhodiola imbricata species exposed to B, as well as an increase in the antioxidant capacity of callus extracts. According to the results, these phenolic compounds, that in $C$. ensiformis reach average values of up to $11.52 \mathrm{mg}$ eq. AG/g biomass, intensely contribute to the defense mechanisms against biotic and abiotic stress [56].

Some authors have linked the phenolic content with stress tolerance, either contributing to indirect light protection or participating directly as antioxidants acting as

Table 4 Statistical analysis of the effect on antioxidant activity

\begin{tabular}{|c|c|c|c|c|}
\hline Treatment & $\begin{array}{l}\text { Antioxidant activity } \\
\left(\mu \mathrm{mol} \text { TE } \mathrm{g}^{-1} \mathrm{FW}\right)\end{array}$ & Standard error of the mean & Lower end of $95 \% \mathrm{Cl}$ & Top end of $95 \% \mathrm{Cl}$ \\
\hline LED B & $59.33 \pm 0.23$ & 0.33 & 57.90 & 60.77 \\
\hline LED R & $30.67 \pm 0.30$ & 0.33 & 29.23 & 32.10 \\
\hline LED 1/3 R-B & $65.33 \pm 0.13$ & 0.33 & 63.90 & 66.77 \\
\hline LED 1/1 R-B & $62.33 \pm 0.22$ & 0.33 & 60.90 & 63.77 \\
\hline LED 3/1 R-B & $33.33 \pm 0.32$ & 0.33 & 31.90 & 34.77 \\
\hline OLED W & $40.33 \pm 0.33$ & 0.33 & 38.90 & 41.77 \\
\hline
\end{tabular}




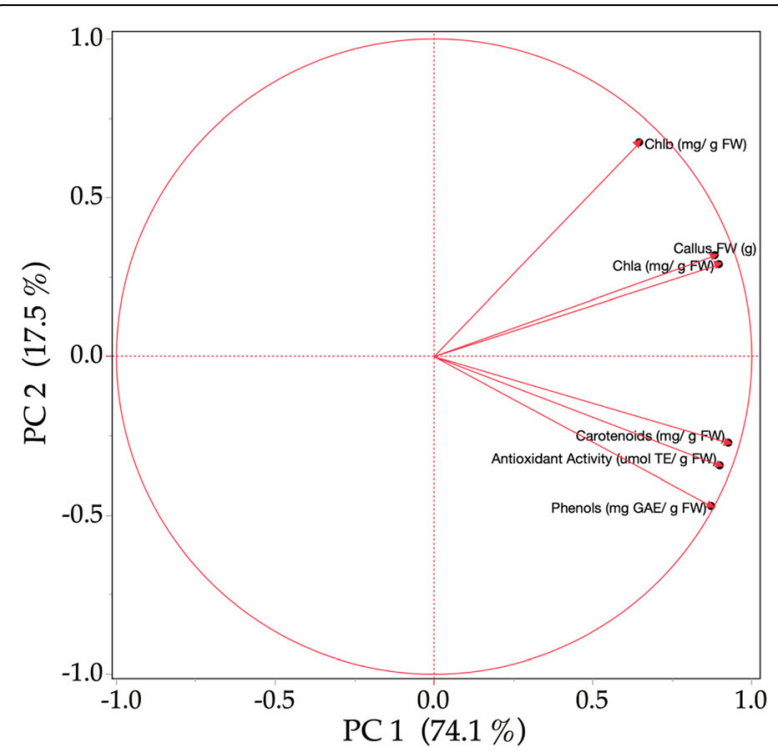

Fig. 5 Principal component analysis for the physiological response of $C$. ensiformis

free radical scavengers due to their reducing properties $[57,58]$. Also, it has proven that phenolic compounds can act as hydrogen donor agents or singlet oxygen extinguishing electrons and metal chelators $[59,60]$.

Figure 6 shows the direct connection between the carotenoid and phenolic contents with the antioxidant activity. According to some authors, this happens because compounds have a positive effect on the antioxidants activity [61, 62]. Furthermore, antioxidants are species that can protect organisms from damage caused by oxidative stress induced by free radicals and in this work, it was found that the combination $1 / 3 \mathrm{R}-\mathrm{B}$ LED is the best response to the production of the compounds evaluated [63]. The presence of these antioxidant compounds is important in C. ensiformis because it favors the production of vital proteins such as the urease and lectin of the plant. These results demonstrate that in vitro culture with a combination of $\mathrm{R}$ and $\mathrm{B}$ in $1 / 3$ proportion favors the production of different compounds such as chlorophyll a/b, phenolic contents, and carotenoids that help in antioxidant activity of the plant.

Table 5 Principal components analysis (PCA)

\begin{tabular}{llll}
\hline Component & Eigenvalue & Percentage & Cumulative percentage \\
\hline 1 & 4521 & 75,359 & 75,359 \\
2 & 1021 & 17,013 & 92,372 \\
3 & 0,218 & 3629 & 96,001 \\
4 & 0,150 & 2499 & 98,500 \\
5 & 0,065 & 1088 & 99,588 \\
6 & 0,025 & 0,412 & 100,000 \\
\hline
\end{tabular}

With this work, it was possible to verify that the initial $\mathrm{pH}$ in the culture medium is a fundamental factor in giving the proper nutrients to calluses and in the production of compounds of interest such as phenols, carotenoids, and antioxidant activity. Due to that, it has been proven that these are fundamental in the growth of plants and that it affects different structures of it [64, 65]. $\mathrm{pH}$ and light are important because they are a significant step for the in vitro production of compounds of importance from this plant, such as urease and lectin. Therefore, it is necessary to carry out new works to investigate how these factors can improve the production of these proteins and how their products could be increased through in vitro cultures.

\section{Conclusions}

It was possible to find the ideal conditions of highest growth under conditions of $\mathrm{pH}$ and light of $C$. ensiformis, to evaluate whether under these conditions the production of compounds of interest such as phenolics and carotenoids occurs. In addition to observing the antioxidant activity as a primary factor in the response of the plant to external factors such as the culture media in the callogenic multiplication.

Determining the in vitro culture conditions of C. ensiformis represents a valuable instrument for the study and production of important metabolites such as phenols and carotenoids. Its independence from environmental conditions allows for the continuous supply of materials, as well as the use of several strategies to stimulate the specific production of these metabolites. The results of this study show that the $\mathrm{pH}$ of the culture medium influences the growth of $C$. ensiformis. In the statistical analysis, it can be seen how the $\mathrm{pH}$ of 5.5 shows a better response to callus growth concerning the other four $\mathrm{pH}$ evaluated.

The highest production of calluses occurs in the $1 / 3$ R-B LED combined light treatment, which showed a significant increase in biomass, followed by $B$, while the least effective was with $\mathrm{W}$. However, the $\mathrm{R}$ treatment, combination 1/1, and 3/1 R-B LED, show similar behaviors. These results are because the 1/3 RB LED combination is repeated in all the bioactive compounds analyzed in this study, which makes this combination the best treatment for obtaining a large amount of biomass and compounds of interest such as phenols, carotenoids, and chlorophyll a/b.

From this study, it could be demonstrated that C. ensiformis not only has a high production of compounds such as urease and lectin but also of compounds such as phenols and carotenoids that are essential for the antioxidant activity of the plant. The in vitro culture of this could be promising to obtain the compounds produced by $C$. ensiformis and it could be of interest at an industrial level as a source of protein. 


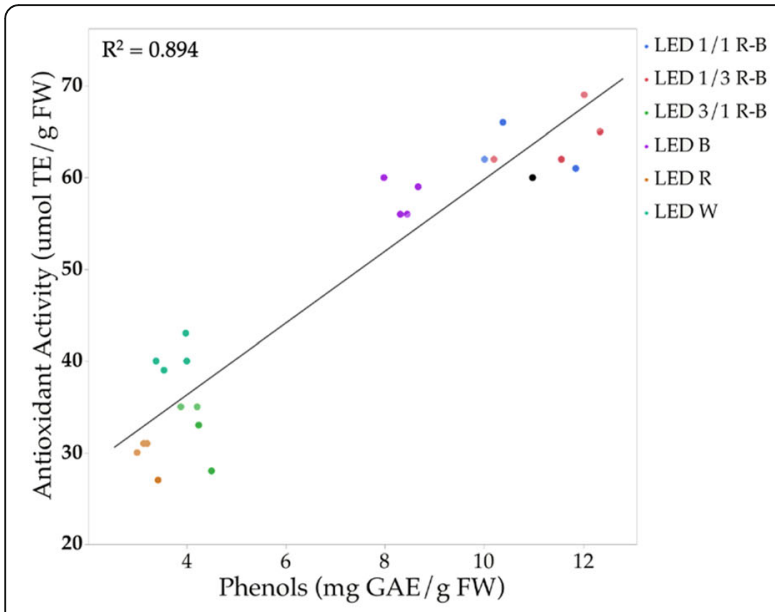

(a)

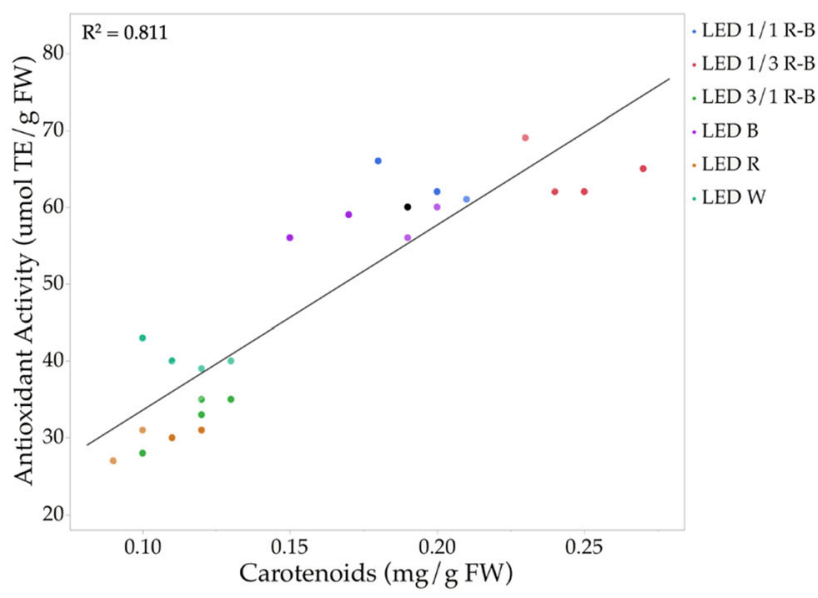

(b)

Fig. 6 Correlations between antioxidant activity and phenolic and carotenoid compounds $(n=18)$

With these results, the efficiency of B in carotenoid production and photosynthetic activity in C. ensiformis was verified. These contrast with the results found by other authors and show once again that the combination of $\mathrm{R}$ and $\mathrm{B}$ with a higher proportion of $\mathrm{B}$ favors a long ratio between oxidizing capacity, phenols, and carotenoids produced in C. ensiformis.

\section{Methods}

\section{Culture conditions}

C. ensiformis was grown in glass jars $(55 \mathrm{~cm}$ in diameter by $70 \mathrm{~cm}$ high) in the Research Center in Environmental Engineering, Universidad de los Andes, from seeds (Semillas-Camposeeds, Bogotá, Colombia). Callogenic induction and callus propagation were achieved using MS salts and vitamins [66] as a basal medium (Thermo Fisher, New Jersey, USA), and supplemented with 3.0\% $(\mathrm{w} / \mathrm{v})$ sucrose (Merck, New Jersey, USA)) and $5 \mathrm{gl}^{-1}$ agar-agar (Merck, New Jersey, USA) callus propagation medium [34].

\section{$\mathrm{pH}$ experiments}

To determine the effect of $\mathrm{pH}$ on callus growth, these were sowed in MS salts (described Section 2.1). The initial $\mathrm{pH}$ of the medium was adjusted with $1 \mathrm{~N} \mathrm{NaOH}$ (Merck, New Jersey, USA) and $0.1 \mathrm{~N} \mathrm{HCl}$ (Merck, New Jersey, USA), then they were autoclaved $\left(121^{\circ} \mathrm{C}, 18 \mathrm{PSI}\right.$, $20 \mathrm{~min}$ ). In this work, the pH between 4.5 and 6.0 was used. For the initial weight, a single range was taken, and it is higher than $0.2500 \mathrm{~g}$ because it is where the important growth effect was observed for the initial mass. All experiments were performed in quadruplicate. Two hundred eighty-eight glass containers were taken, sterilized at $121^{\circ} \mathrm{C}, 18$ PSI $\left(\mathrm{lbf} \mathrm{in}^{-2}\right.$ ) for $20 \mathrm{~min}$, weighed empty, and then with the explant, they were immediately cultured at $23 \pm 1{ }^{\circ} \mathrm{C}$, with continuous white light for 30 days. After this time, the calluses were weighed again, and the biomass growth over time was obtained by weight difference.

\section{LED experiments}

For LED (light-emitting diode) experiments, black painted polypropylene boxes (33 X $52 \times 31 \mathrm{~cm})$ were used with red (R; peak at $657 \mathrm{~nm}$ ), and blue (B; peak at $455 \mathrm{~nm}$ ) LEDs (ILUMAX, Shenzhen, China). Six light treatments were applied, which were: $100 \%$ white light (control) (LED W) and several red (R) to blue (B) ratios, as follows: $100 \% \mathrm{~B}, 100 \% \mathrm{R}, 25 \% \mathrm{R}$ and $75 \% \mathrm{~B}(1 / 3 \mathrm{R}-\mathrm{B})$, $75 \% \mathrm{R}$ and $25 \% \mathrm{~B}(3 / 1 \mathrm{R}-\mathrm{B})$, and $50 \% \mathrm{R}$ and $50 \% \mathrm{~B}(1 / 1$ $\mathrm{R}-\mathrm{B})$, and LED W. In each treatment, three glass containers with $25 \mathrm{ml}$ of MS salts containing $0.25 \mathrm{~g}$ of fresh callus were seeded. Calluses were grown for 60 days, until the callogenic mass increased and exposed to light treatments for 30 days. The laboratory conditions were a relative humidity of $52 \%$, with an average temperature of $20 / 16^{\circ} \mathrm{C}$ (light/day), the plants were exposed to a $12 \mathrm{~h} /$ $12 \mathrm{~h}$ photoperiod. Then, callus biomass was analyzed and used for the determination of total phenolics, chlorophyll, carotenoids, and antioxidant activity.

\section{Total phenolics}

The content of total phenolic in callus extract was determined by the Folin-Ciocalteu method [67]. Fresh calluses $(200 \mathrm{mg})$ were extracted with methanol using a Soxhlet apparatus. $1 \mathrm{~mL}$ of methanolic callus extract was mixed with $5 \mathrm{ml}$ of Folin-Ciocalteu reagent (Sigma-Aldrich, St. Louis, United States) (diluted 10-fold) and $4 \mathrm{ml}$ of sodium carbonate solution $\left(7500 \mathrm{mgl}^{-1}\right)$. Then, the absorbance at $765 \mathrm{~nm}$ was measured after $1 \mathrm{~h}$. The calibration curve was prepared with methanolic gallic acid 
solutions, which were mixed with the same reagents described above, and after $1 \mathrm{~h}$ the absorbance was measured. Total phenolic content in callus methanolic extracts was expressed in Gallic Acid Equivalents (GAE) by the equation:

$$
T P=\frac{(c * V)}{F W}
$$

Where, TP is the total content of phenolic compounds expressed like mg GAE $\mathrm{g}^{-1} \mathrm{FW}, \mathrm{c}$ is the concentration of gallic acid deduced from the calibration curve (mg $\mathrm{ml}^{-1}$ ), V is extract volume (ml), and FW is the weight of the fresh callus $(\mathrm{g})$.

\section{Chlorophyll and carotenoids determination}

The content of chlorophyll and carotenoids was quantified in acetone extract. In other words, $100 \mathrm{mg}$ of fresh callus were crushed in $5 \mathrm{ml}$ of chilled acetone $(80 \% \mathrm{v} / \mathrm{v})$. Then, the extract was centrifuged at $2500 \mathrm{rpm}$ for $5 \mathrm{~min}$, and absorbance of the supernatant was read at 660, 645, and $470 \mathrm{~nm}$. The content of Chla, Chlb, and carotenoids was calculated in $\mathrm{mg} \mathrm{g}^{-1}$ FW biomass using the following equations, according to Wellburn [68].

$$
\begin{aligned}
& \text { CHla }=\left\{\frac{\left[12.21\left(A_{660}\right)-2.81\left(A_{645}\right)\right] V}{(1000 * F W)}\right\} \\
& C H l b=\left\{\frac{\left[20.13\left(A_{645}\right)-5.03\left(A_{660}\right)\right] V}{(1000 * F W)}\right\} \\
& \text { Carotenoid }=\left\{\frac{\left[1000\left(A_{470}\right)-3.27(C H l a)-104(\mathrm{CHlb})\right] V}{(1000 * F W)}\right\}
\end{aligned}
$$

Where $\mathrm{A}_{660}, \mathrm{~A}_{645}$, and $\mathrm{A}_{470}$ are the value of absorbance in $\mathrm{nm}, \mathrm{V}$ is the extract volume, and $\mathrm{FW}$ is the weight of the fresh callus.

\section{Antioxidant activity capacity}

The antioxidant activity of callus methanolic extract was determined by $2,7^{\prime}$ - dichlorodihydrofluorescein diacetate $(\mathrm{DCFH})$ probe, which reacts indiscriminately with reactive oxygen species (ROS) and reactive nitrogen species (RNS) generated by the compound azo, 2,2'-diazobis (2amidinopropane dihydrochloride) (AAPH) in an aqueous medium and forms the fluorescent compound 2,7dichlorofluorescein (DCF). The antioxidants in the samples capture ROS and RNS and reduce the fluorescence emitted by DCF. $50 \mu \mathrm{l}$ of a $0.3 \mathrm{M}$ AAPH solution, $50 \mu \mathrm{l}$ of a $2.4 \mathrm{mM}$ DCFH ethanolic solution, $2850 \mu \mathrm{l}$ of $75 \mathrm{mM}$ phosphate buffer ( $\mathrm{pH} 7.4$ ), and $50 \mu \mathrm{l}$ of the methanolic callus extract (described Section 2.4), which was obtained by mixing $0.3 \mathrm{~g}$ of macerated fresh callus using liquid nitrogen and mortar, with $2 \mathrm{ml}$ of $10 \mathrm{mM}$ phosphate buffer ( $\mathrm{pH} 7.0)$. The intensity of fluorescence emitted during the first 10 min was read and compared with the intensity emitted in the absence of the sample ( $\lambda$ excitation: $326 \mathrm{~nm}$, a $\lambda$ emission: $432 \mathrm{~nm}$ and $10 \mathrm{~nm}$ slit). The results are expressed as $\mathrm{mg} \mu \mathrm{mol}$ of Trolox Equivalents (TE) per $g$ of fresh callus biomass by constructing a standard curve using different concentrations of TROLOX ${ }^{\bullet}[69]$.

\section{Statistical analysis}

All statistical analysis were performed using two softwares. Statgraphics 18 centurion software was used for the analysis of the effect of $\mathrm{pH}$ on callus growth. For the analysis of the effect of light on the growth of calluses and the effect of the production of bioactive substances, the software JMP-Pro version 13.1.0 was used. All experiments were performed in quadruplicate.

\section{Supplementary information}

Supplementary information accompanies this paper at https://doi.org/10. 1186/s12896-020-00642-x.

\section{Additional file 1.}

Additional file 2 .

\section{Abbreviations}

$A_{660}, A_{645}, A_{470}$ : Value of absorbance (nm); AAPH: Azo, 2,2'-diazobis (2amidinopropane dihydrochloride); ANOVA: Analysis of variance; B: Blue light; C: Concentration of gallic acid ( $\left.\mathrm{mg} \mathrm{ml}^{-1}\right)$; Chla: Chlorophyll a;

Chlb: Chlorophyll b; Cl: Confidence interval; DCF: 2,7-dichlorofluorescein; DCFH: 2,7'- dichlorodihydrofluorescein diacetate; df: Degrees of freedom: FW: Weight of the fresh callus (g); GAE: Gallic Acid Equivalents; PCA: Principal component analysis; PFR: Far-red light; R: Red light; RNS: Reactive nitrogen species; ROS: Reactive oxygen species; TE: Trolox Equivalents; TP: Total content of phenolic compounds expressed like mg (GAE g $\left.{ }^{-1} \mathrm{FW}\right)$; V: Extract volume (ml); W: White light

\section{Acknowledgments}

This work was carried out with financial support from the Department of Civil and Environmental Engineering of the Universidad de los Andes. This publication was partially made possible by the call for proposals $\mathrm{Cl}-0120$ :

"Publish your new knowledge or expose your new creations" from the Office Vice President for Research and Creation at Universidad de los Andes.

\section{Authors' contributions}

JFS, YC, and JEL planned and designed the experiments, JFS and JEL carried out the experiments, JFS, YC, and JEL wrote the manuscript. All authors have read and approved the entire manuscript.

\section{Funding}

This research received no external funding.

\section{Availability of data and materials}

All data generated and analyzed during this study are included in the published article.

Ethics approval and consent to participate Not applicable. 


\section{Consent for publication}

Not applicable.

\section{Competing interests}

The authors declare that they have no competing interests.

\section{Author details}

'Dept. of Civil and Environmental Engineering, Universidad de los Andes, Carrera 1Este \#19A-40, Bogotá, Colombia 111711. ²Dept. of Environmental Engineering, Universidad de Medellín, Carrera 87 \#30-65, Medellín, Colombia 050026.

Received: 29 May 2020 Accepted: 5 August 2020

Published online: 10 September 2020

\section{References}

1. Carlini CR, Ligabue-Braun R. Ureases as multifunctional toxic proteins: A review. Toxicon. 2016;110:90-109.

2. Sá CA, Vieira LR, Pereira Almeida Filho LC, Real-Guerra R, Lopes FC, Souza TM, et al. Risk assessment of the antifungal and insecticidal peptide Jaburetox and its parental protein the Jack bean (Canavalia ensiformis) urease. Food Chem Toxicol. 2020;136:110977.

3. Sridhar KR, Seena S. Nutritional and antinutritional significance of four unconventional legumes of the genus Canavalia - A comparative study. Food Chemistry. 2006;99(2):267-88.

4. Summer JB. The isolation and crystallization of the enzyme urease preliminary paper. J Biol Chem. 1926;69(2):435-41.

5. Fujiuchi N, Matoba N, Matsuda R. Environment Control to Improve Recombinant Protein Yields in Plants Based on Agrobacterium-Mediated Transient Gene Expression. Front Bioeng Biotechnol [Internet]. 2016:4 [citado 20 de abril de 2020] Disponible en: https://www.ncbi.nlm.nih.gov/ pmc/articles/PMC4781840/.

6. Debergh PC. Effects of agar brand and concentration on the tissue culture medium. Physiol Plant. 1983;59(2):270-6.

7. Schenk N, Hsiao K-C, Bornman CH. Avoidance of precipitation and carbohydrate breakdown in autoclaved plant tissue culture media. Plant Cell Reports. 1991;10(3):115-9.

8. Tuan PA, Thwe AA, Kim YB, Kim JK, Kim S-J, Lee S, et al. Effects of White, Blue, and Red Light-Emitting Diodes on Carotenoid Biosynthetic Gene Expression Levels and Carotenoid Accumulation in Sprouts of Tartary Buckwheat (Fagopyrum tataricum Gaertn.). J Agric Food Chem. 2013;61(50):12356-61.

9. Lobiuc A, Vasilache V, Oroian M, Stoleru T, Burducea M, Pintilie O, et al. Blue and Red LED Illumination Improves Growth and Bioactive Compounds Contents in Acyanic and Cyanic Ocimum basilicum L. Microgreens. Molecules. 2017;22(12):2111.

10. Kapoor S, Raghuvanshi R, Bhardwaj P, Sood H, Saxena S, Chaurasia OP. Influence of light quality on growth, secondary metabolites production and antioxidant activity in callus culture of Rhodiola imbricata Edgew. J Photochemistry Photobiology B: Biol. 2018;183:258-65.

11. Świeca M, Dziki D. Improvement in sprouted wheat flour functionality: effect of time, temperature and elicitation. Int J Food Sci Technol. 2015; 50(9):2135-42

12. Pasqua G, Manes F, Monacelli B, Natale L, Anselmi S. Effects of the culture medium $\mathrm{pH}$ and ion uptake in in vitro vegetative organogenesis in thin cell layers of tobacco. Plant Sci. 2002;162(6):947-55.

13. Raven JA, Smith FA. Nitrogen assimilation and transport in vascular land plants in relation to intracellular pH regulation. New Phytol. 1976;76(3): 415-31

14. Lang B, Kaiser WM. Solute content and energy status of roots of barley plants cultivated at different pH on nitrate- or ammonium-nitrogen. New Phytol. 1994;128(3):451-9.

15. Xiang J, Zheng J, Zhou Z, Suo H, Zhao X, Zhou X, et al. Enhancement of red emission and site analysis in Eu2+ doped new-type structure Ba3CaK(PO4)3 for plant growth white LEDs. Chemical Engineering J. 2019;356:236-44.

16. Zhou N, Gao P, Yang Y, Zhong Y, Xia M, Zhang Y, et al. Novel orange-red emitting phosphor Sr8ZnY(PO4)7:Sm3+ with enhanced emission based on $\mathrm{Mg} 2+$ and $\mathrm{Al} 3+$ incorporation for plant growth LED lighting. J Taiwan Institute Chem Engineers. 2019;104:360-8.

17. Zhou Z, Zheng J, Shi R, Zhang N, Chen J, Zhang R, et al. Ab Initio Site Occupancy and Far-Red Emission of Mn4+ in Cubic-Phase La(MgTi)1/2O3 for Plant Cultivation. ACS Appl Mater Interfaces. 2017;9(7):6177-85.
18. Wright M. Experts examine plant response to SSL and market potential at horticultural conference [Internet]. LEDs Magazine. 2019 [citado 5 de febrero de 2020]. Disponible en: https://www.ledsmagazine.com/manufacturingservices-testing/standards/article/16695503/experts-examine-plant-responseto-ssl-and-market-potential-at-horticultural-conference-magazine.

19. Carvalho RF, Takaki M, Azevedo RA. Plant pigments: the many faces of light perception. Acta Physiol Plant. 2011;33(2):241-8.

20. Abidi F, Girault T, Douillet O, Guillemain G, Sintes G, Laffaire M, et al. Blue light effects on rose photosynthesis and photomorphogenesis. Plant Biol. 2013;15(1):67-74.

21. Massa GD, Kim H-H, Wheeler RM, Mitchell CA. Plant Productivity in Response to LED Lighting. HortScience. 2008;43(7):1951-6.

22. Nhut DT, Takamura T, Watanabe H, Okamoto K, Tanaka M. Responses of strawberry plantlets cultured in vitro under superbright red and blue lightemitting diodes (LEDs). Plant Cell Tissue Organ Culture. 2003;73(1):43-52.

23. Li H, Tang C, Xu Z. The effects of different light qualities on rapeseed (Brassica napus L.) plantlet growth and morphogenesis in vitro. Scientia Horticulturae. 2013;150:117-24

24. Chen X, Yang O, Song W, Wang L, Guo W, Xue X. Growth and nutritional properties of lettuce affected by different alternating intervals of red and blue LED irradiation. Scientia Horticulturae. 2017:223:44-52.

25. Eskins K, Jiang CZ, Shibles R. Light-quality and irradiance effects on pigments, light-harvesting proteins and Rubisco activity in a chlorophyll- and lightharvesting-deficient soybean mutant. Physiol Plant. 1991;83(1):47-53.

26. Leong T-Y, Anderson JM. Effect of light quality on the composition and function of thylakoid membranes in Atriplex triangularis. Biochimica et Biophysica Acta (BBA) - Bioenergetics. 1984;766(3):533-41.

27. Senger $\mathrm{H}$, Bauer $\mathrm{B}$. The influence of light quality on adaptation and function of the photosynthetic apparatus. Photochem Photobiol. 1987;45(S1):939-46.

28. Wang XY, Xu XM, Cui J. The importance of blue light for leaf area expansion, development of photosynthetic apparatus, and chloroplast ultrastructure of Cucumis sativus grown under weak light. Photosynthetica. 2015;53(2):213-22

29. Costa BS, Jungandreas A, Jakob T, Weisheit W, Mittag M, Wilhelm C. Blue light is essential for high light acclimation and photoprotection in the diatom Phaeodactylum tricornutum. J Exp Bot enero de. 2013:64(2):483-93.

30. Brown CS, Schuerger AC, Sager JC. Growth and photomorphogenesis of pepper plants under red light-emitting diodes with supplemental blue or far-red lighting. J Am Soc Hortic Sci. 1995;120(5):808-13.

31. Goins GD, Yorio NC, Sanwo MM, Brown CS. Photomorphogenesis, photosynthesis, and seed yield of wheat plants grown under red lightemitting diodes (LEDS) with and without supplemental blue lighting. J Exp Bot. 1997:48(7):1407-13.

32. Kato MC, Hikosaka K, Hirose T. Leaf discs floated on water are different from intact leaves in photosynthesis and photoinhibition. Photosynthesis Res. 2002;72(1):65

33. Jirakiattikul $Y$, Rithichai $P$, Songsri $O$, Ruangnoo $S$, Itharat $A$. In vitro propagation and bioactive compound accumulation in regenerated shoots of Dioscorea birmanica Prain \& Burkill. Acta Physiol Plant. 2016;38(10):249.

34. Saldarriaga JF, López J, Lopera C, Botero LR. Efecto del pH y el peso inicial de implante sembrado en la multiplicación callogénica de Canavalia ensiformis. Avances en Ciencias e Ingeniería. 2014;5(2):73-83.

35. Williams RR, Taji AM, Winney KA. The effect of Ptilotus plant tissue on pH of in vitro media. Plant Cell Tiss Organ Cult. 1990;22(3):153-8.

36. Ruenroengklin N, Zhong J, Duan X, Yang B, Li J, Jiang Y. Effects of Various Temperatures and $\mathrm{pH}$ Values on the Extraction Yield of Phenolics from Litchi Fruit Pericarp Tissue and the Antioxidant Activity of the Extracted Anthocyanins. Int J Mol Sci. 2008;9(7):1333-41.

37. Isah T, Umar S, Mujib A, Sharma MP, Rajasekharan PE, Zafar N, et al. Secondary metabolism of pharmaceuticals in the plant in vitro cultures: strategies, approaches, and limitations to achieving higher yield. Plant Cell Tiss Organ Cult. 2018;132(2):239-65.

38. Dussert S, Verdeil J-L, Rival A, Noirot M, Buffard-Morel J. Nutrient uptake and growth of in vitro coconut (Cocos nucifera L.) calluses. Plant Science. 1995: 106(2):185-93.

39. Yatazawa M, Furuhashi K, Shimizu M. Growth of callus tissue from rice-root in virto. Plant Cell Physiol. 1967;8(3):363-73.

40. Jayaraman S, Daud NH, Halis R, Mohamed R. Effects of plant growth regulators, carbon sources and $\mathrm{pH}$ values on callus induction in Aquilaria malaccensis leaf explants and characteristics of the resultant calli. J Forestry Res. 2014;25(3):535-40. 
41. Rastogi R, Sawhney VK. The Role of Plant Growth Regulators, Sucrose and $\mathrm{pH}$ in the Development of Floral Buds of Tomato (Lycopersicon esculentum Mill.) Cultured in vitro. J Plant Physiol. 1987;128(3):285-95.

42. Nagella P, Murthy HN. Establishment of cell suspension cultures of Withania somnifera for the production of withanolide A. Bioresource Technology. 2010;101(17):6735-9.

43. Naik PM, Manohar SH, Praveen N, Murthy HN. Effects of sucrose and pH levels on in vitro shoot regeneration from leaf explants of Bacopa monnieri and accumulation of bacoside $A$ in regenerated shoots. Plant Cell Tiss Organ Cult. 2010;100(2):235-9.

44. Majerus F, Pareilleux A. Production of indole alkaloids by gel-entrapped cells of Catharanthus roseus in a continuous flow reactor. Biotechnol Lett. 1986; 8(12):863-6.

45. Karsai I, Bedo Z, Hayes PM. Effect of induction medium pH and maltose concentration on in vitro androgenesis of hexaploid winter triticale and wheat. Plant Cell Tiss Organ Cult. 1994;39(1):49-53.

46. Smith $\mathrm{DL}$, Krikorian AD. Low external pH replaces 2,4-D in maintaining and multiplying 2,4-D-initiated embryogenic cells of carrot. Physiol Plant. 1990; 80(3):329-36.

47. Sánchez $F$, Honrubia M, Torres P. Effects of pH, water stress and temperature on in vitro cultures of ectomycorrhizal fungi from Mediterranean forests. Cryptogamie Mycologie. 2001;22(4):243-58.

48. Pfündel $E$, Baake $E$. A quantitative description of fluorescence excitation spectra in intact bean leaves greened under intermittent light. Photosynth Res. 1990;26(1):19-28.

49. Ahmed HA, Yu-Xin T, Qi-Chang Y. Optimal control of environmental conditions affecting lettuce plant growth in a controlled environment with artificial lighting: A review. South Afr J Botany. 2020;130:75-89.

50. Cosgrove DJ. Rapid Suppression of Growth by Blue Light: OCCURRENCE, TIME COURSE, AND GENERAL CHARACTERISTICS. Plant Physiol. 1981;67(3): 584-90

51. Giliberto L, Perrotta G, Pallara P, Weller JL, Fraser PD, Bramley PM, et al. Manipulation of the Blue Light Photoreceptor Cryptochrome 2 in Tomato Affects Vegetative Development, Flowering Time, and Fruit Antioxidant Content. Plant Physiology. 2005;137(1):199-208.

52. Li Q, Kubota C. Effects of supplemental light quality on growth and phytochemicals of baby leaf lettuce. Environ Experimental Botany. 2009; 67(1):59-64.

53. Senger $\mathrm{H}$. The effect of blue light on plants and microorganisms. Photochem Photobiol. 1982;35(6):911-20.

54. Hoffmann AM, Noga G, Hunsche M. Alternating high and low intensity of blue light affects PSII photochemistry and raises the contents of carotenoids and anthocyanins in pepper leaves. Plant Growth Regul. 2016;79(3):275-85

55. Chiappero J, del R CL, Sosa Alderete LG, Palermo TB, Banchio E. Plant growth promoting rhizobacteria improve the antioxidant status in Mentha piperita grown under drought stress leading to an enhancement of plant growth and total phenolic content. Industrial Crops and Products. 2019;139: 111553

56. Awika JM, Rooney LW, Wu X, Prior RL, Cisneros-Zevallos L. Screening Methods To Measure Antioxidant Activity of Sorghum (Sorghum bicolor) and Sorghum Products. J Agric Food Chem. 2003;51(23):6657-62.

57. Agati G, Tattini M. Multiple functional roles of flavonoids in photoprotection. New Phytol. 2010;186(4):786-93.

58. Khalil N, Fekry M, Bishr M, El-Zalabani S, Salama O. Foliar spraying of salicylic acid induced accumulation of phenolics, increased radical scavenging activity and modified the composition of the essential oil of water stressed Thymus vulgaris L. Plant Physiol Biochem. 2018;123:65-74.

59. Oh J, Jo H, Cho AR, Kim S-J, Han J. Antioxidant and antimicrobial activities of various leafy herbal teas. Food Control. 2013;31(2):403-9.

60. Riachi LG, De Maria CAB. Peppermint antioxidants revisited. Food Chemistry. 2015;176:72-81.

61. Caprioli G, Maggi F, Bendif H, Miara MD, Cinque B, Lizzi AR, et al. Thymus lanceolatus ethanolic extract protects human cells from t-BHP induced oxidative damage. Food Funct. 2018;9(7):3665-72.

62. Jabri Karoui I, Msaada K, Abderrabba M, Marzouk B. Bioactive compounds and antioxidant activities of ThymeEnriched refined corn oil. J Agr Sci Tech. 2016:18:79-91.

63. Čanadanović-Brunet JM, Djilas SM, Ćetković GS, Tumbas VT, Mandić Al, Čanadanović VM. Antioxidant activities of different Teucrium montanum L. extracts. Int J Food Sci Technol. 2006;41(6):667-73.
64. Buchanan BB, Gruissem W, Jones RL. Editores. Biochemistry \& Molecular Biology of plants. 1st ed. Hoboken: Wiley; 2002. p. 1408.

65. Pallardy SG. Physiology of Woody plants. Edición: 3. Amsterdam: Academic Press; 2007. p. 464

66. Murashige T, Skoog F. A revised medium for rapid growth and bio assays with tobacco tissue cultures. Physiol Plant. 1962;15(3):473-97.

67. Misra P, Toppo DD, Gupta N, Chakrabarty D, Tuli R. Effect of antioxidants and associate changes in antioxidant enzymes in controlling browning and necrosis of proliferating shoots of elite $\{$ Jatropha\} curcas $\{L\}$. Biomass Bioenergy. 2010;34(12):1861-9.

68. Wellburn AR. The Spectral Determination of Chlorophylls $a$ and b, as well as Total Carotenoids, Using Various Solvents with Spectrophotometers of Different Resolution. J Plant Physiol. 1994;144(3):307-13.

69. Zapata K, Cortes FB, Rojano BA. Polifenoles y Actividad Antioxidante del Fruto de Guayaba Agria (Psidium araca). Información tecnológica. 2013; 24(5):103-12.

\section{Publisher's Note}

Springer Nature remains neutral with regard to jurisdictional claims in published maps and institutional affiliations.
Ready to submit your research? Choose BMC and benefit from:

- fast, convenient online submission

- thorough peer review by experienced researchers in your field

- rapid publication on acceptance

- support for research data, including large and complex data types

- gold Open Access which fosters wider collaboration and increased citations

- maximum visibility for your research: over $100 \mathrm{M}$ website views per year

At BMC, research is always in progress.

Learn more biomedcentral.com/submissions 